\title{
TEMPAT-TEMPAT SAKRAL DAN PENERAPAN SAWORA DALAM MASYARAKAT KAMPUNG ISENEBUAI DI KAWASAN TAMAN TELUK CENDERAWASIH
}

\author{
Irman Rumengan \\ Program Studi Magister Manajemen Sumberdaya Pantai Universitas Diponegoro \\ Email : irman08.08@gmail.com
}

\begin{abstract}
Cultural heritage is an important value owned by some communities in the area of Teluk Cenderawasi National Park. One of which is the legacy of important places owned by Isenebuai village community. Isenebuai village community has Sawora or "oath" to organize and manage the resources, location owned. The implementation of Sawora by Isenebuai village community has been done for a long time. The implementation of Sawora has also been applied to the villagers and the community outside of Isenebuai village, with the rules made by the adat elders and community leaders of Isenebuai village. Sawora and important places of Isenebuai village are a very unique cultural treasure owned by the village community specifically and owned by the Cendrawasih Bay National Park Area in general. In general, Sawora has similarities with Sasi but has a very different implementation base, because Sawora is the original product of Isenebuai village community culture that has existed since long time (before the introduction of Sasi).
\end{abstract}

Key words: sacred place, Sawora, Isenebuai, Cenderawasih Bay National Park

\section{Latar Belakang}

Taman Nasional Teluk

Cenderawasih (TNTC) merupakan

kawasan taman nasional laut terluas yang ada di Indonesia dengan luas 1.453 .500 ha terdiri dari sekitar 55.800 ha luas daratan pulau, 12.400 ha pesisir pantai, 80.000 ha bentangan terumbu karang, dan 1.305.300 ha luas lautan (Anoimous, 2003 dalam Warsito dan Nurapriayanto, 2008). Posisi kawasan TNTC terletak diantara dua Provinsi yaitu Papua dan Papua Barat. Terdapat pula masyarakat lokal maupun masyarakat pendatang sebagai penghuni kawasan TNTC yang sudah sejak lama mendiami kawasan tersebut (Warsito dan Nurapriayant, 2008).

Masyarakat lokal dan pendatang yang berada di dalam kawasan TNTC merupakan penduduk yang mendiami suatu pemukiman di dalam kawasan TNTC dalam kurun waktu tertentu dan umumnya adalah masyarakat yang masih menggantungkan hidupnya pada hasil-hasil alam yang bersumber dari darat dan laut. Berhubung sebagian besar pemukiman berada di kawasan TNTC berlokasi dipesisir pantai, aktivitas pemenuhan kebutuhan hidup sebagian besar diarahkan pada pencarian sumber makanan yang ada di laut.

Kampung Isenebuai merupakan salah satu kampung yang masuk dalam kawasan TNTC dan juga merupakan salah satu kampung yang sudah ada sejak lama di pulau Rumberpon. Masyarakat yang mendiami kampung Isenebuai merupakan masyarakat yang sudah sejak lama mendiami pulau Rumberpon, dimana pulau tersebut merupakan salah satu pulau yang ada pada kawasan TNTC. Sama seperti halnya dengan masyarakat pada umumnya, masyarakat lsenebuai memiliki peraturan pemerintahan dan juga aturan kebudayaan yang masih dipegang sampai saat ini. Peraturan-peraturan kebudayaan tersebut dapat berupa peraturan tempat, maupun peraturan untuk mencari pemenuhan hidup di alam.

Pemenuhan kebutuhan hidup dengan berburu binatang di darat serta mengambil hasil laut dilakukan oleh masyarakat 
Isenebuai. Pengambilan biota laut seperti ikan, teripang, lola dan juga biota laut lainnya dilakukan hampir setiap hari menggunakan alat dan bahan yang bersifat tradisional maupun modern. Alat-alat yang digunakan tersebut ada yang dapat digolongkan ramah lingkungan dan juga dihapus yang dapat digolongkan tidak ramah lingkungan.

Penggunaan alat dan bahan pencari biota laut yang tidak ramah lingkungan mengakibatkan penurunan biota laut, yang secara tidak langsung mengakibatkan penurunan jumlah hasil tangkapan oleh masyarakat, di samping adanya pelanggaran memasuki kawasan/ tempat yang diangap sakral oleh masyarakat. Berdasarkan beberapa permasalah tersebut, maka masyarakat Isenebuai membuat Sawora (yang sebenarnya telah dilaksanakan oleh nenek moyang dari dahulu sampai sekarang) atau peraturan untuk mengatur tempat, cara, maupun hasil sumberdaya untuk memenuhi kebutuhan hidup masyarakat Isenebuai sendiri maupun masyarakat luar yang masuk pada kawasan sekitar kampung Isenebuai. Dengan adannya penerapan Sawora di kampung Isenebuai, perlu adanya informasi mengenai penerapan Sawora.

\subsection{Tujuan dan Manfaat}

Adapun Tujuan pembuatan makalah yang berjudul "Tempat-tempat Sakral dan Penerapan Sawora dalam Masyarakat Kampung Isenebuai di Kawasan Taman Nasional Teluk Cenderawasih," yaitu untuk mengetahui penerapan Sawora yang ada di Kampung Isenebuai dan tempattempat yang dianggap sakral oleh masyarakat kampung Isenebuai. Adapun manfaat yang diharapkan dapat memberikan informasi mengenai penerapan Sawora dan tempat-tempat penting yang ada di kampung Isenebuai.

\section{Kawasan Taman Nasional Teluk Cenderawasih}

Taman Nasional merupakan salah satu bentuk kawasan konservasi yang mempunyai tiga fungsi dan peranan, yaitu sebagai perlindungan sistem penyangga kehidupan, pengawetan keanekaragaman jenis tumbuhan dan satwa, serta pemanfaatan secara lestari sumberdaya alam hayati dan ekosistemnya (Hami N. dkk., 2009).

Salah satu kawasan konservasi laut di Papua adalah kawasan Taman Nasional Teluk Cenderawasih (TNTC) yang terletak di dua kabupaten, yaitu Kabupaten Teluk Wondama (Provinsi Papua Barat) dan Kabupaten Nabire (Provinsi Papua) (Gambar 1). TNTC merupakan salah satu taman nasional yang ditetapkan sebagai Taman Nasional berdasarkan Keputusan Menteri Kehutanan Nomor 472/KptsII/1993 tanggal 2 September 1993. Kawasan dengan luas 1.453 .500 ha terdiri dari sekitar 55.800 ha luas daratan pulau, 12.400 ha pesisir pantai, 80.000 ha bentangan terumbu karang, dan 1.305.300 ha luas lautan (Anoimous, 2003 dalam Warsito dan Nurapnayanto, 2008). Kawasan TNTC juga terbagi dalam 5 tipe ekosistem, yaitu ekosistem hutan tropis daratan/pulau, ekosistem hutan mangrove, ekosistem hutan pantai, ekosistem padang lamun. dan ekosistem terumbu karang (BBTNTC, 2009, dalam Hamid dkk., 2009)

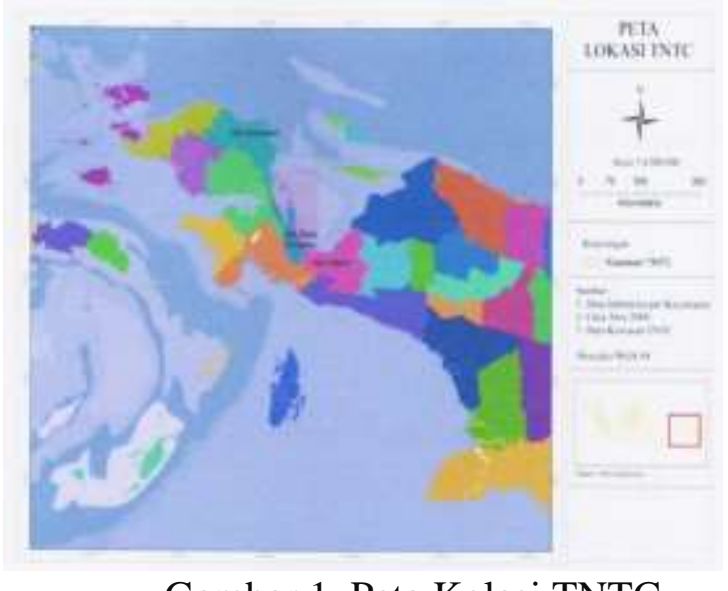

Gambar 1. Peta Kolasi TNTC

Dengan tingginya potensi sumberdaya alam yang ada di kawasan TNTC maka perlu adannya pengelolaan yang menyeluruh dari tingkat bawah 
sampai dengan tingkat atas. Pengelolaan taman masional ini tentunya tidak lepas dari masyarakat yang tinggal di kawasan Taman Nasional, sehingga masyarakat yang tinggal di kawasan Taman Nasional ini juga memiliki peran penting dalam menjaga kelancaran program-program dan taman nasional itu sendiri, dimana Program-program dari taman nasional ditujukan untuk masyarakat yang tinggal dikawasan itu sendiri (Hamid dkk., 2009).

Hamid dkk. (2009) menyatakan bahwa masyarakat yang ada di kawasan TNTC belum memperoleh pelayanan yang maksimal dimana saran dan prasarana pendidikan serta tenaga pendidikan yang masih sangat terbatas. Pelayanan kesehatan yang diterima oleh masyarakat pesisir dikawasan TNTC masih sangat kurang. Keadaan ini disebabkan sedikitnya jumlah tenaga medis dan terbatasnya prasarana kesehatan yang ada di kampung-kampung. Secara administrasi, kawasan TNTC berada di Kabupaten Nabire, Provinsi Papua dan Kabupaten Teluk Wondama Provinsi Papua Barat dengan jumlah penduduk berdasarkan distrik dapat dilihat pada tabel 1 .

Tabel 1. Jumlah Penduduk Berdasarkan Distrik

\begin{tabular}{|c|c|c|c|}
\hline No & Distrik & KK & Penduduk \\
\hline 1 & Naikere & 218 & 861 \\
\hline 2 & Wondiboy & 334 & 1.398 \\
\hline 3 & Rasiey & 572 & 2.342 \\
\hline 4 & Kuri Wamesa & 374 & 1.607 \\
\hline 5 & Wasior & 1.729 & 7.841 \\
\hline 6 & TelukDuari & 335 & 1.365 \\
\hline 7 & Roon & 334 & 1.736 \\
\hline 8 & Windesi & 318 & 1.464 \\
\hline 9 & Nikiwar & 215 & 824 \\
\hline 10 & Wamesa & 183 & 703 \\
\hline 11 & Roswar & 144 & 666 \\
\hline 12 & Rumberpon & 339 & 1.472 \\
\hline 13 & SougJaya & 210 & 861 \\
\hline & Jumlah & 5.305 & 23.140 \\
\hline
\end{tabular}

Sumber BPS Kabupaten Teluk Wondama (2009) dalam (Hamid dkk. 2009).
Mata pencaharian utama masyarakat kawasan TNTC adalah sebagai nelayan. Keadaan ini menunjukkan ketergantungan masyarakat akan sumber daya laut sangat besar. Kegiatan mencari biota laut masih bersifat mengambil secara keseluruhan biota yang ditemukan saat melakukan aktifitas pencarian biota laut, tanpa memperhatikan keberlanjutan dari biota laut tersebut. Kegiatan ini dilakukan bukan hanya oleh masyarakat yang ada di dalam kawasan TNTC, namun nelayan-nelayan dari luar kawasan juga masuk ke dalam kawasan untuk mencari biota laut.

\subsection{Kepemilikan Laut dan Darat Kawasan TNTC \\ Kepemilikan atas kawasan TNTC} terdiri dari dua tipe, yaitu berdasarkan batas administrasi kampung dan batas adat. Dimana secara batas adminstrasi kampung seperlunya adalah diberlakukan aturan pemerintah secara umum, sedangkan secara batas adat, aturan yang diberlakukan adalah secara aturan adat yang sudah sejak dahulu ada sebelum adanya aturan pemerintah.

Hak kepemilikan atas laut dibatasi oleh batas kampung. Perairan laut yang berada di depan sebuah kampung dimiliki oleh suku yang ada di kampung tersebut. Setiap orang yang berasal dari luar kampung yang ingin memancing harus meminta ijin terlebih dahulu (Hamid dkk. 2009).

\subsection{Kampung Isenebuai}

Menurut Laporan WWF (2013), kampung Isenebuai adalah kampung yang terletak di wilayah administratif Distrik Rumberpon Kabupaten Teluk Wondama. Kata Isenebuai yang berarti "Mereka mempunyai kelakuan atau adat yang baik". Kata ini berasal dari bahasa Wandamen. Kampung Isenebuai memiliki beberapa marga yang tinggal, dimulai dari margamarga yang memiliki kampung/tempat Isenebuai hingga marga pendatang yang datang karena faktor perkawinan kekeluargaan dan alasan lainnya. 
Sejarah perjalanan marga pendiri kampung Isenebuai menurut cerita dan tetua-tetua marga, kampung Isenebuai pertama kali didirikan oleh beberapa marga ash sang di antarannya adalah marga Wandau, Myosimun, Naba, dan Kabia. Dari keempat marga ini, hanya marga Wanda yang sampai sekarang mempunyai banyak keturunan, dan ketiga marga lainnya seperti marga Myosimun sudah tidak memiliki keturunan lagi, marga Naba menyisahkan satu keturunan, dan marga Kabia meninggalkan dua keturunan. Marga asli yang tinggal di kampung Isenebuai sendiri mempunyai cerita yang panjang hingga mereka bisa sampai di Isenebuai. Kampung Lama, tempat marga dan moyang ini pertama kali bermukim adalah kampung Snebai yang terletak di sekitar teluk Saibini. Namun karena pada saat itu datanglah seekor ular naga "Inuri" dan ular itu kemudian memangsa mereka, lalu tersisalah moyang mereka yang bernama Arwam. Kemudian ia berpindah ke Bogirin demi menghindari kejaran ular naga tersebut, di sana ia membentuk sebuah kampung. Selanjutnya karena pada masa itu sering terjadi perang untuk memperebutkan budak dan harta, masyarakat dari Bogirin pun berlayar dan berperang dengan lokasi tujuan ke kampung di daratan (Momiwaren) (perang itu dalam sejarah dikenal dalam sebutan "perang Hongi"), dengan menyeberangi lautan, Namun karena pengetahuan akan teknik mendayung sangat terbatas. Pada malam itu, mereka berangkat saat cuaca gelap sehingga saat mereka mendayung perahu mereka, tetapi perahu mereka arah menuju daratan tempat mereka tinggal, karena malam begitu gelap sehingga mereka tidak mengenali daratan mereka dan keluarga mereka, maka mereka membunuh anak dan istri mereka di kampungnya sendiri. Hingga saat matahari terbit barulah mereka tersadar karena telah membunuh keluarganya sendiri. Pada akhirnya mereka menyesalinya dan berpindah lagi ke daerah tanjung Anyeri, dan di sana bersama-sama dengan marga
Myosimun mendirikan sebuah kampung yang kemudian diberi nama Manipi. Kemudian dengan alasan bahwa di kampung Manipi lokasinya tidak aman, dua marga ini berpindah tempat lagi ke sungai Anggrisiwui. Di sana mereka bertemu dengan marga Naba dan Kabia, dan selanjutnya mereka mendirikan sebuah kampung yang kemudian diberi nama Isanebuai.

Sedangkan marga pendatang Selain dari keempat marga tersebut, yakni marga Wandau, Mysimun, Naba, dan Kabia, ada juga marga-marga pendatang (9 marga) yang datang kerena faktor perkawinan dan perang Hongi., yaitu marga Rumbiak, Wara, Kaikatui, Marani, Mambor, Sikun, Paduai, Sayori, Sewasemaniyai.

Selain dari keempat marga tersebut, terdapat sembilan marga pendatang, yaitu Rumbiak, Wara, Kaikatui, Marani, Mambor, Sikun, Paduai, Sayori, Sewasemaniyai. Marga pendatang tersebut datang kerena faktor perkawinan dengan penduduk setempat, disamping sebagai akibat dari perang (Hongi).

\subsection{Sawora di Kampung Isenebuai}

Istilah Sawora atau Sumpah dalam bahasa Indonesia merupakan suatu aturan atau larangan yang mengatur mengenai lokasi, cara menggunakan alat mencari pemenuhan kebutuhan hidup, waktu, sumberdaya alam, serta orang-orang yang diberlakukan Sawora. Sawora (sumpah) merupakan suatu warisan kebudayaan yang sampai sekarang masih dilakukan oleh masyarakat kampung Isenebuai. Tidak jauh berbeda dengan pengertian Sasi (yang lebih dikenal masyarakat umum di Indonesia), Sawora merupakan suatu sistem budaya yang dihasilkan langsung oleh masyarakat kampung Isenebuai. Aturan main serta aturan-aturan yang mengatur mengenai apa yang perlu di Sawora memiliki kesamaan dengan Sasi. Sawora sebenarnya merupakan suatu aturan yang benar-benar muncul oleh masyarakat kampung Isenebuai dan baru 
disekitaran kampung Isenebuai yang mengerti tentang Sawora.

Pembentukan Sawora dilakukan oleh para pemuka adat dan juga tokoh-tokoh masyarakat kampung Isenebuai yang dianggap layak untuk diajak membuat suatu Sawora. Tidak semua masyarakat dapat membuat Sawora, namun semua masyarakat wajib mentaati aturan jika sudah adanya Sawora. Sawora lokasi penangkapan ikan, lokasi berburu, maupun lokasi bertani dan bercocok tanam diatur sepenuhnya untuk memenuhi kebutuhan hidup masyarakat Isenebuai atau pada alasan lain yaitu untuk membangun rumah ibadah di kampung Isenebuai, dimana mayoritas merupakan masyarakat yang beragama Kristen Protestan. Alasan utama di buat Sawora yaitu agar adanya kedisplinan masyarakat untuk tidak mengeksploitasi secara berlebihan sumberdaya alam (darat maupun laut) yang ada di sekitar kampung Isenebuai. Hal ini juga bertujuan agar sumberdaya tersebut tidak habis dan dapat dimanfaatkan secara terus menerus oleh masyarakat kampung hingga anak cucu mereka. (WWF, 2013).

Lokasi-lokasi serta aturan main dalam Sawora memiliki keterbatasan ruang dan waktu, ada beberapa lokasi yang akan di Sawora secara permanen (selamannya) dan ada lokasi yang di Sawora berkala (dibuka pada waktu tertentu). Lokasi Sawora yang berkala umumnya terletak di laut dimana pada saat buka Sawora, masyarakat beramai-ramai memanen hasil dan hasil dari panen tersebut dikumpulkan dan dijual untuk membangun infrastruktur yang ada di kampung (rumah ibadah, jalan, dan bangunan umum lainnya).

Proses demi proses dilaksanakan oleh para tetua adat dan tokoh masyarakat di kampung Isenebuai, melalui pengumpulan tetua-tetua adat serta tokoh kampung, penentuan lokasi dan sumberdaya yang perlu di Sawora (sumpah), pelaksanaan ritual di kampung, dan pelaksanaan ritual di lokasi yang di Sawora, Setelah itu lokasi serta sumberdaya yang di Sawora diumumkan di gereja agar semua masyarakat mengetahui.

Pelaksanaan Sawora sudah sejak lama dilaksanakan oleh masyarakat kampung Isenebuai, baik untuk kepentingan masyarakat dalam hal pemenuhan kebutuhan hidup maupun dalam hal keberlanjutan alam dimana mereka mengantungkan hidup meraka sejak dahulu sampai dengan sekarang. Hukuman keras berupa sanksi adat serta denda akan diberlakukan pada pelangar aturan Sawora. Hukuman sanksi adat untuk masyarakat kampung Isenebuai sendiri berupa pengusiran, pengucilan dari kampung; sedangkan denda berupa denda uang atau biaya yang harus dibayar sesuai tingkat pelangaran yang dibuat. Adapun sanksi untuk masyarakat luar yaitu berupa penyitaan alat penangkapan dan denda berupa uang.

\subsection{Tempat-tempat Sakral yang Dianggap penting oleh Masyarakat Isenebuai \\ Menurut laporan WWF (2013),} masyarakat di kampung Isenebuai memiliki tempat-tempat penting yang dianggap pamali atau keramat atau sakral dan sangat berkaitan dengan sejarah perjalanan nenek moyang mereka. Selain tabu, tempat-tempat tersebut juga memiliki beberapa peraturan adat yang konon apabila dilanggar akan mendatangkan masalah, seperti memotong kayu, buang air (kecil), dan jatuh di tempat itu, bahkan menceritakannya kepada orang lain. Adapun tempat-tempat itu adalah sebagai berikut:

\section{Teluk Saibini}

Teluk ini merupakan tempat yang paling keramat, karena di tempat ini terdapat bekas-bakas peninggalan dari tuan tanah di pulau Rumberpon. Peninggalannya berupa batu penggayu dan batu Kasuari. Tanjung ini juga merupakan tempat bermainnya kedua anak perempuannya yakni Sarera dan Sewaroki. Dengan pergi ke tempat ini digunakan perahu dengan 
mesin tempel (Jonson), waktu yang ditempuh adalah +3 (tiga) jam perjalanan.

2. Teluk Mondis atau Inuri

Dahulu tanjung ini merupakan tempat tinggal ular Inuri, akan tetapi ular itu telah pergi karena digigit oleh Kima. Ular tersebut ditipu oleh seorang wanita cantik. Karena begitu cantiknya, ular itu rela melakukan apa saja yang dikehendaki si wanita, sampai suatu saat wanita itu menyuruhnya mengambil kima. Akan tetapi ular tersebut tidak tahu bahwa kima yang dimaksud adalah kima raksasa. Saat ular itu "Inuri" hendak mengambilnya, ia digigit hingga saki. Karena sakit lalu ular itu mengibas ekornya hingga membekas di dinding batu sampai sekarang ini. Jarak tempuh yang dibutuhkan untuk sampai di tanjung ini adalah \pm 4-5 jam, menggunakan perahu tempel (Jonson).

3. Tanjung Mabubi

Ini merupakan tempat sakral. Pengunjun ilarang mengotori dan memotong pohon di areal sekitar tanjung tersebut. Jarak tempuh yang dibutuhkan untuk sampai di tanjung ini adalah \pm 5-6 jam, menggunakan perahu tempel (Jonson).

4. Mamuram

Dipercaya tempat ini merupakan tempat tinggal manusia purba, ditandai dengan tumbuhnya serumpun bambu. Jarak yang ditempuh hingga sampai ke tempat ini adalah \pm 5-6 jam, lalu perjalanan dilanjutkan dengan berjalan kaki kurang lebih 1 (satu) kilometer perjalanan.

5. Tanjung Anasaini

Tanjung ini dianggap sebagai ekor dari ular "Inuri", karena itu di tempat ini dilarang keras untuk membuang air kecil, dan melakukan aktivitas asusila. Jarak tempuh yang dibutuhkan untuk sampai di tanjung ini adalah \pm 2-3 jam, menggunakan perahu tempel (jonson).

6. Bukit Mundusani

Tempat manusia purba tinggal, dengan wajahnya berbentuk salib, dan kebiasaannya suka menculik manusia dan membawanya ke rumahnya "Mundusani". Jarak tempuh yang dibutuhkan untuk sampai di garis pantai tempat ini adalah \pm
30 menit, menggunakan perahu tempel (Jonson), kemudian perjalanan dilanjutkan dengan berjalan kaki yang memakan waktu sekitar 2-3 jam.

7. Marsanbra

Marsanbra berupa gua perlindungan alam. Jarak tempuh yang dibutuhkan untuk sampai di garis pantai tempat ini adalah \pm 30 menit, menggunakan perahu tempel (Jonson). Kemudian perjalanan dilanjutkan dengan berjalan kaki dan menaiki gunung. Perjalanan ini memakan waktu sekitar 2-3 jam. Tempat ini berdekatan dengan bukit Marsanbran yang berjarak sekitar 30-60 menit perjalanan.

Selain tempat-tempat penting, seperti tempat keramat dan sakral, tempat-tempat dinana masyarakat mencari makan untuk memenuhi kebutuhan mereka sehari-hari juga ada suatu tempat yang tidak kalah pentingnya. Tempat ini merupakan warisan dari moyang mereka yang diturunkan secara turun-temurun, hingga sekarang. Tempat dipakai bersama untuk memenuhi kebutuhan hidup sehari-hari secara turun temurun meskipun dalam hal kepemilikan merupakan milik suatu marga tertentu, kecuali daerah laut. Tempat-tempat penting itu antara lain: Dusun sagu Anorsi, Dusun sagu Serimari, Dusun sagu Seriwepori, Dusun Wariwei, Dusunsagu Wadofesi, Dusun sagu Yayubi, Dusun sagu Imboron, dan Dusun Seriangrisi.

Selain dusun-dusun sagu, daerah laut juga menjadi yang begitu penting bagi kelangsungan hidup masyarakat di kampung ini. Kegiatan keseharian masyarakat adalah pergi mencari ikan ke daerah pasir panjang tanjung Anyeri. Tempat merupakan tempat yang strategis, karena terdapat area tutupan karang yang baik, dan terdapat padang lamun yang begitu luas, sehingga tempat ini sangat kaya akan biota-biota lautnya, seperti teripang, udang, kima, penyu, duyung, dan goropa. 


\subsection{Pengertian Sasi menurut Masyarakat TNTC}

Sasi merupakan bentuk aturan pengelolan sumberdaya alam berbasis masyarakat yang telah dilakukan oleh masyarakat pedesaan di Maluku. Sasi merupakan kearifan tradisional yang hadir dalam sosok peraturan adat yang mempertahankan nilai-nilai lama dalam menjaga kelestarian lingkungan yang sudah berkembang sejak abad XVII. Istilah Sasi berasal dari kata sanksi (witness) mengandung pengertian tentang larangan pemanfaatan sumberdaya alam tertentu tanpa izin dalam jangka waktu tertentu yang secara ekonomis bermanfaat bagi masyarakat. Dengan demikian Sasi memiliki dimensi temporal dan lambang (atribut) yang bersama-sama membuat institusi Sasi mengikat.

Hukum Adat Sasi merupakan sebuah aturan permainan dalam mengelola sumberdaya alam di desa-desa di Maluku. Hukum Adat Sasi tersebut menjadi pedoman dalam mengelola sumberdaya alam yang ada di Kepulauan Maluku dan merupakan bagian dan masyarakat adat setempat (Sofyaun A. 2013). Akses memanen atau mengambil basil perikanan laut diatur dan disepakati bersama oleh masyarakat mengandung unsur-unsur larangan mengambil hasil perikanan laut pada jangka waktu tertentu. Maksud pengaturan tersebut adalah agar pemanenan hasil perikanan laut dilakukan pada waktu yang tepat. Bentuk aturan ini bagi masyarakat Maluku dikenal dengan istilah adat Sasi (Wattimena dan Papilaya, 2005). Menurut Novaczek dan Harkes (1998) dalam Sofyaun A (2012), daerah laut yang diatur oleh Sasi memiliki kondisi ekologi yang lebih baik dibandingkan dengan daerah laut yang tidak di-Sasi (seperti kondisi terumbu karang yang rusak). Oleh sebab itu, kcberadaan kearifan lokal diharapkan mampu mewujudkan pengelolaan dan pemanfaatan sumberdaya alam yang berkelanjutan.

Menurut Pattinama dan Pattipelony (2003) dalam Sofyan (2012), Sasi merupakan tradisi masyarakat yang memiliki nilai hukum yang substantif yaitu larangan untuk tidak mengambil hasil laut maupun hasil hutan sampai pada waktu tertentu. Sasi dapat memiliki nilai hukum, karena memiliki norma dan aturan yang berhubungan dengan cara, kebiasaan, tata perilaku dan adat yang memuat unsur etika dan norma. Nilai-nilai hukum yang substansial dalam sistem Sasi sebagai inti dan hukum adat tersebut sebagai berikut; (a) penggunaan hak seseorang secara tepat menurut waktu yang ditentukan; (b) pencegahan timbulnya sengketa antara sesama negeri; (c) pemeliharaan dan pelestarian alam demi peningkatan kesejahteraan bersama; (d) kewajiban untuk memanjakan hasil laut dan darat; dan (e) mengurangi timbulnya kejahatan berupa pencurian sumberdaya alam.

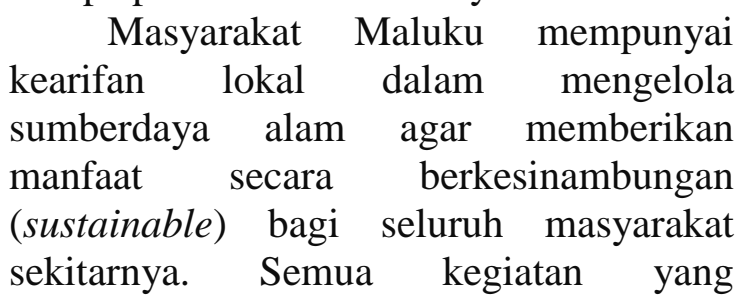
memanfaatkan sumberdaya alam baik darat maupun laut saling terkait yang diatur dalam hukum adat (Wahyono, 2000) dalam Sofyan (2012). Sasi diberlakukan karena sumberdaya alam di pulau-pulau kecil sangat terbatas, sementara kebutuhan anggota masyarakat terus meningkat. Jadi dapat dikatakan bahwa antara jumlah penduduk dengan ketersediaan sumberdaya alam tidak seimbang, sehingga lahirlah pemikiran bahwa sumberdaya alam yang terbatas tersebut harus dikelola secara arif dan bijaksana demi kepentingan bersama. Tujuan utama Sasi adalah untuk menjaga keseimbangan antara alam, manusia dan dunia spiritual, dimana pelanggaran atas pelaksanaan Sasi akan memperoleh sanksi dunia spiritual dan sanksi masyarakat.

Khusus untuk masyarakat di kawasan TNTC, Sasi merupakan suatu aturan yang dibuat sendiri oleh masyarakat untuk menutup ataupun membatasi suatu pemanfaatan sumberdaya yang ada di 
wilayah adat masyarakat kampung adapun maksud penutupan wilayah adalah untuk kegiatan kerohanian (membangun gereja) dan juga untuk kegiatan pembangunan fasilitas-fasilitas kampung. Aturan Sasi umumnya dibuat oleh para tetua kampung (orang yang dituakan) dan pelaksanaan dilaksanakan oleh semua warga masyarakat kampung.

\subsection{Penerapan Sasi di TNTC}

Asal mula pengunaan nama Sasi di kawasan TNTC masih simpang siur (belum jelas) sampai sekarang, belum adanya penelitian yang secara spesifik mengungkapkan asal mula penggunaan nama Sasi di kawasan TNTC, namun adaptasi penggunaan nama Sasi mulai di berlakukan/dikenal setelah adannya zonasi yang ditetapkan di dalam kawasan TNTC. Masyarakat awalnya mengenal Sasi dengan hak ulayat, baik itu hak ulayat darat maupun hak ulayat laut yang mencakup seluruh sumberdaya darat dan sumberdaya laut.

Tidak secara keseluruhan Sumberdaya alam di kawasan TNTC dimasukan kedalam sistem Sasi, dan sumberdaya laut yang ada, hanya beberapa sumberdaya yang telah disepakati bersama untuk diberlakukan sistem Sasi diantarannya yaitu biota teripang, Lobster, dan lola (Gambar 2), serta lokasi Sasi yang diberlakukan hanya di beberapa lokasi saja (hanya beberapa kampung yang menerapkan sistem Sasi).
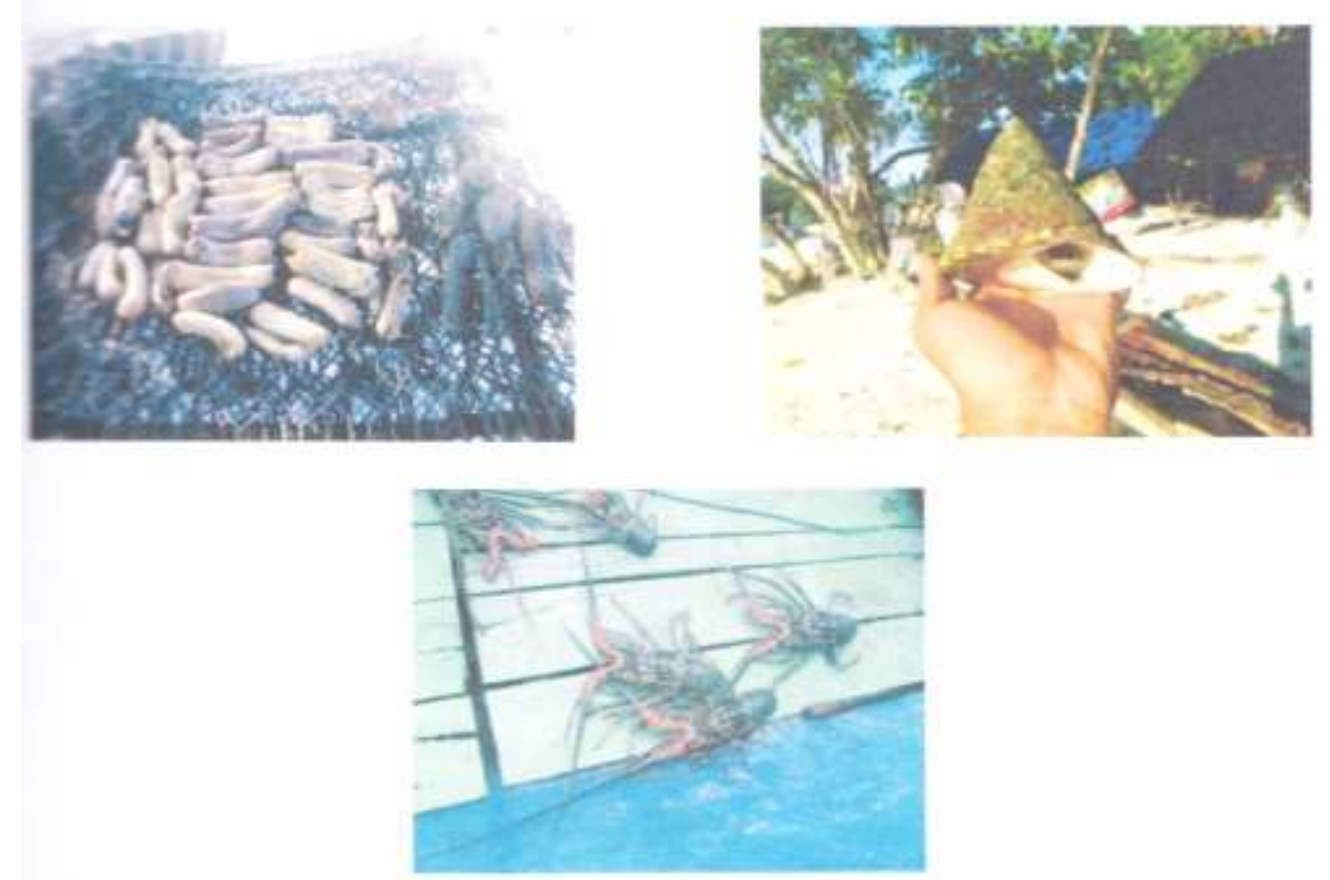

Gambar 2. Biota yang di Sasi (Sumber. Foto Pribadi)

Kampung-kampung yang sudah menerapkan sistem Sasi di kawasan TNTC yaitu kampung Napan Yaur, Kampung Yomber, dan Kampung Roswar (gambar 3). Selain ketiga kampung tersebut, kampung-kampung yang lain belum melaksanakan sistem Sasi, dan juga ada beberapa kampung seperti kampung Syabes, Yomakan, Isenebuai dan beberapa kampung lainnya yang masih dalam proses pembuatan sistem Sasi.

Penerapan sistem Sasi di kampung Yomber dan Roswar telah dilaksanakan sejak dahulu (secara turun temurun) dengan sistem Sasi menggunakan dasar agama sebagai dasr pembuatan aturan dan juga pemberian sanksi terhadap pelanggar aturan Sasi. Lokasi Sasi yang diterapkan 
oleh kampung Yomber dan Roswar terletak di sekitar pulau Roswar dengan masa penutupan lokasi antara beberapa bulan sampai dengan beberapa Tahun ke depan.

Untuk penerapan Sasi di kampung Napan Yaur berbeda dengan di kampung Yomber dan Roswar, di mana untuk kampung Napan Yaur, penerapan sistem Sasi masih dalam proses pengesahan (belum ada Sasi resmi). Penentuan lokasi Sasi yaitu di sekitar kampung Napan Yaur, dan lamanya penutupan lokasi antara beberapa bulan sampai penutupan permanen (selamanya).

\section{Simpulan}

Dari hasil pembahasan di atas, dapat disimpulkan bahwa masyarakat kampung Isenebuai memiliki sistem kebudayaan dalam hal mengatur sumberdaya yang disebut Sawora (sumpah). Penerapan Sawora oleh masyarakat kampung sudah dilaksanakan sejak lama, dimana aturan untuk mengatur lokasi, sumberdaya, waktu dan orang yang di Sawora merupakan prioritas dan Sawora di kampung Isenebuai. Sawora memiliki keterbatasan waktu dan ruang. Umumnya

Sawora memiliki kesamaan dengan Sistem Sasi, dimana pelaksanaan serta aturan-aturan yang diberlakukan memiliki banyak kesamaan dengan Sasi. Banyak kesarnaan sistem serta aturan main antara Sawora dan Sasi. Namun pada dasarnya kedua hal tersebut memiliki perbedaan yang sangat mendasar, yaitu Sawora lebih dikenal di kampung Isenebuai dan telah dilaksanakan sejak.

Selain memiliki Sawora, masyarakat kampung Isenebuai memiliki beberapa tempat-tempat yang menurut kepercayaan masyarakat kampung merupakan tempattempat warisan nenek moyang yang disakralkan oleh masyarakat. Beberapa lokasi yang disakralkan terletak di daratan pulau Rumberpon, di lautan dekat kampung, serta di pulau-pulau sekitar kampung Isenebuai.
Sawora dan tempat-tempat penting yang dimiliki oleh masyarakat kampung Isenebuai merupakan salah satu dan kekayaan budaya yang dimiliki kawasan Taman Nasional Teluk Cenderawasih. Kebudayaan yang kaya serta aturan menjaga sumberdaya darat serta perairan merupakan warisan kebudayaan yang dikenal oleh masyarakat luar/umum sebagai Sasi.

\subsection{Saran}

Perlu adanya penelitian mendalam terkait penerapan Sawora dan tempattempat penting di kawasan TNTC dengan mengumpulkan informasi langsung di lokasi Kampung Isenebuai.

\section{Dafyar Pustaka}

Hamid N. dkk. 2009. "Persepsi Masyarakat Lampung Kwatisore di Kabupaten Nabire Tentang Taman Nasional Teluk Cenderawasih Manokwari." Jurusan PerikananFPPK UNIPA.

Moniaga S. 2002. Hak-hak Masyarakat Adat dan Masalah serta Kelestarian Lingkungan Hidup di Indonesia. Jakarta: Media Pemajuan Hak Asasi Manusia.

Sofyan A. 2012. Analisis Kelembagaan Sasi dalam Pengelolaan Perikanan Tangkap di Kecamatan Seram Timur. Bogor: Fakultas Perikanan dan Ilmu Kelautan IPB.

Warsito H dan Nurapriayanto I. 2008. Kajian Sosial Ekonomi Budidaya Teripang oleh Masyarakat Aisandami, Papua. Manokwari: Balai Penelitian Kehutanan Manokwari.

WWF. 2013. "Laporan Pemetaan Partisipatif Tempat Penting di TNTC." Kabupaten Wasior. 